\title{
Carmen Toribio Marin \\ Imágenes del jardín en la Holanda del Renacimiento y el Manierismo
}

\author{
Palabras clave: Jardín holandés, paisaje, jardinería, tratados, Renacimiento, Manierismo
}

En este trabajo se resumen los principales registros visuales existentes en fuentes bibliográficas sobre los jardines holandeses de la segunda mitad del XVI y la primera del XVII. La investigación se inicia con datos de las referencias literarias de la época sobre el jardin por parte de humanistas y escritores neerlandeses destacados. La selección de imágenes se basa en gran parte en la inspección de todos los tratados importantes de jardinería holandeses, como los de Vredeman de Vries, Van der Groen, Hans Puec, Philip Vingboons o A. van Langelaar y, así mismo, los de alemanes con gran repercusión en Holanda, como el caso de Joseph Furttenbach, o franceses como el de Mollet. En lo relativo a láminas y grabados se han seguido las fuentes bibliográficas y de archivos indicadas en el propio trabajo y en sus notas. Con todo ello se compone un conjunto de referencias que, aunque no es exhaustivo, si es original y altamente representativo de los materiales existentes sobre el tema.

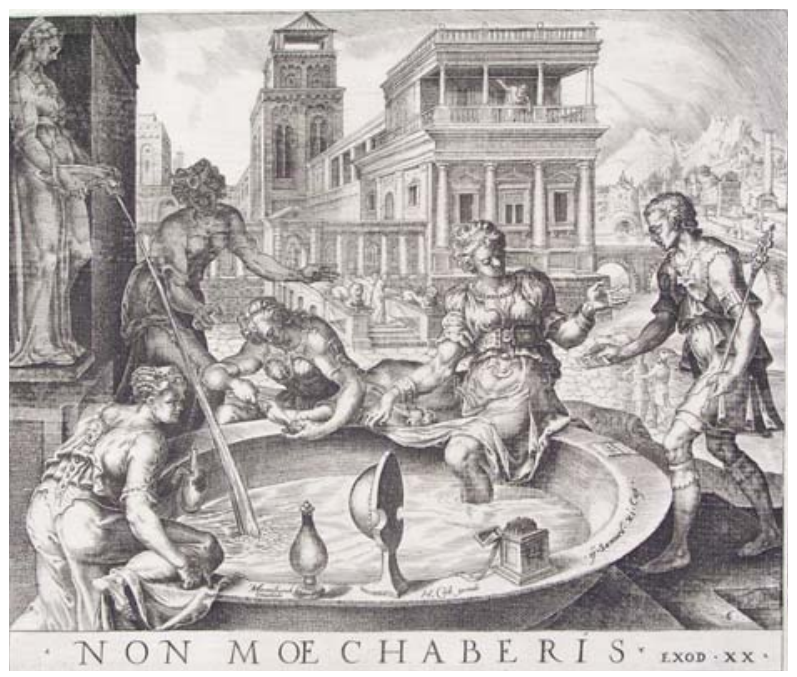

Izquierda. Maerten van Heemskerck, Batseba recibe la carta de David. S XVII.

Derecha. Maerten van Heemskerck. Susana y los viejos. 1563.

Gerard de Jode. La historia de Narciso. 1560.

Carmen Toribio es arquitecta, profesora de Historia del Jardin en la Universidad Camilo José Cela. Alumna de doctorado en el Dpto de Composición de la ETSAM.

\section{Literatura y grabados}

a información disponible sobre el jardín Lholandés del XVI es muy escasa, a pesar de que humanistas como Erasmus, Lipsius y Marnix van St. Aldegonde mostraron gran interés en el tema en sus escritos filosóficos. ${ }^{1}$ Erasmo quizás fue el que realizó algunas de las descripciones más pormenorizadas de jardines con elementos compositivos clásicos en varios de sus Coloquios. En relación con el agua, en su Fiesta Santa recurrirá a un tema clásico: una fuente purificadora de la que brotan canales que imitan el mármol y que dividen el espacio en partes iguales. ${ }^{2} \mathrm{El}$ agua que riega el jardín, cuyas virtudes lustrales son repetidamente puestas de manifiesto, finalmente se dirige a la casa, donde se emplea en la cocina y en llevar los residuos hasta el alcantarillado. Ante el asombro de Tim, uno de los interlocutores, Eusebio, el propietario del jardín, abogará por el uso racional del agua, desde una perspectiva asombrosamente moderna. Esta unión entre lo simbólico y lo práctico, lo bello y lo útil o lo cristiano y lo económico, será inherente al jardín holandés del XVII.

Aunque se tiene constancia de que existieron jardines trazados con criterios renacentistas en algunas cortes del XVI, como la de los Nassau en Breda o la de Felipe de

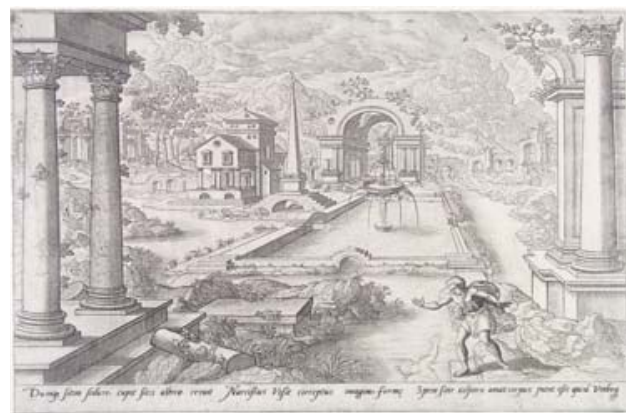




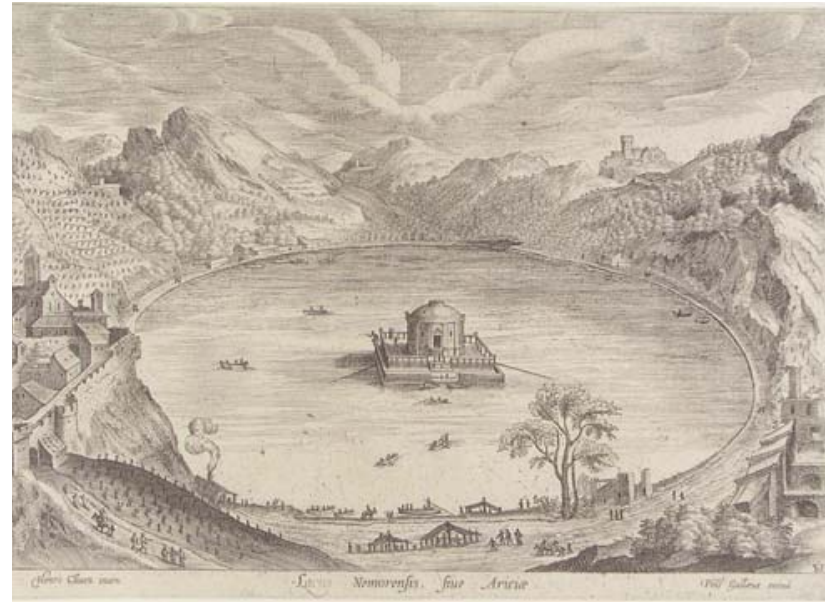

Izquierda. Hendrik van Cleve. Lacus

Nemorensis, siuae Ariciae .S. XVI.

Derecha. Johan Wierix. Composita. S. XVI.

Baptista van Doetechum. Castillo con puente levadizo. 1559-1561.Museo Boijmans van Beuningen

Frans Hogenberg. La Toma de Poppelsdorf. 1572. Museo Boijmans van Beuningen.
Borgoña en Utrecht, las únicas imágenes que podrian darnos una idea de su posible su aspecto proceden de algunos grabados contemporáneos. Algunos, procedentes de ilustradores como Rafael Saedeler o Maerten van Heemskerk, representan escenas mitológicas o bíblicas (Amor, el Baño de Betsabé o Susana y los Viejos) y muestran elementos de clara inspiración clásica: personajes junto a fuentes elaboradas seguramente poco frecuentes en los jardines construidos, o templetes redondos rodeados por agua y amplios estanques con fuente central (en los que es frecuente la alusión a figuras mitológicas como la de Narciso). La obra de Hendrik van Cleve (1525-1589) Rurarium Ruinarum varii prospectus ruriumq. aliquot delineationes proporciona una particular visión de algunas ruinas clásicas, como la del mítico lago Nemi, en el que el autor sitúa un templo circular en su centro, construido sobre una isla cuadrada accesible sólo por embarcación. La imagen de templete clásico circular sobre el agua se repetirá en la obra de Wienx (Composita), pero sin embargo será un motivo de realización poco frecuente. Frente a estas imágenes que mostraban espacios idealizados de inspiración clásica dificilmente adaptables al clima y la geografia holandesa y probablemente nunca construidos, otro tipo de obras se aproximaba seguramente más a la realidad. Los grabados de escenas cortesanas, de guerra y especialmente aquellos que tienen que ver con la actividad agrícola y los meses del año proporcionan información quizás más próxima a la materialización real de los jardines de la época.

En un ámbito de representación supuestamente más realista, son muy numerosos los grabados que, como el del Castillo con puente levadizo de Doetechum, muestran una edificación defensiva rodeada por agua (a veces construida sobre una isla, en otras ocasiones directamente sobre un foso de contorno cuadrangular o circular) y accesible únicamente por un puente de madera levadizo. Existen múltiples variaciones en cuanto al acceso al castillo, bien sea mediante una edificación intermedia (como en el caso de la representación de Lovenstein que realiza Visscher), directamente o a través de una plaza o patio de acceso. El tipo era habitual en la Europa medieval, y está también figurado en escenas de guerra contra localidades como Poppelsdorf (próxima a Bonn), en las que el agua se empleaba asimismo como un eficaz sistema de defensa. ${ }^{3}$ La solución de situar cerramientos concéntricos de agua debía ser también reiterada y aparece en numerosas ocasiones asociado a bastidas como la del castillo de Wouw en Bergen op Zoom. Desarrollado en un extenso recinto amurallado de cinco lados rodeado por agua, al que se accede desde una singular isla triangular, contaba en su interior con otro cerramiento acuático, jardines y
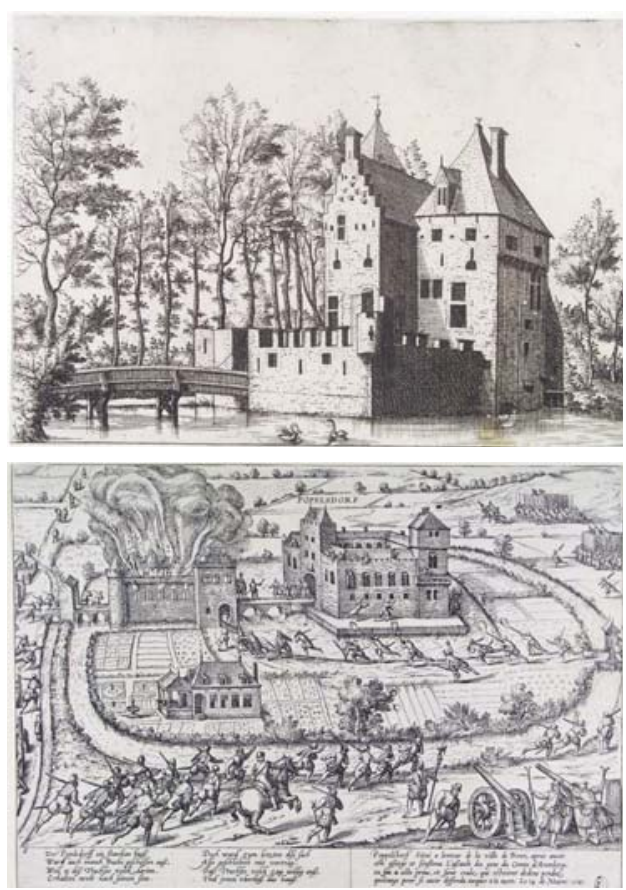


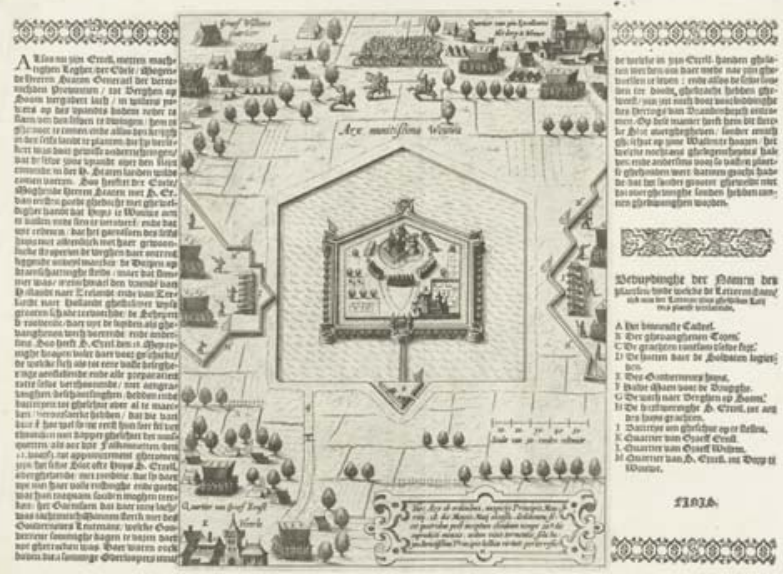

Baptista van Doetechum.

La Toma del Castillo de Wouw en Bergen op Zoom. 1605. Rijksmuseum Amsterdam

Nicollas de Bruyn. Las Edades del Hombre: XX. S. XVI. varias edificaciones, una de ellas situada sobre un foso interior. En cualquier caso, habitualmente el espacio disponible en el interior de los recintos construidos sobre fosos era escaso, por lo que el jardin se desarrollaba preferiblemente en el exterior, separado del castillo.

En un género diferente, las imágenes de escenas agrícolas y cortesanas muestran jardines de aspecto medieval que comparten rasgos comunes: la compartimentación del espacio, el cerramiento mediante emparrados o túneles de verdor y la presencia de arquitectura efimera en forma de pabellones construidos sobre los árboles. La presencia del agua se produce de formas variadas: se reitera la aparición de la fuente de tazas, quizás más como símbolo que como elemento construido real, pero además el agua aparece en pesquerias y sobre todo en canales que delimitan espacios diferenciados del jardin o superficies sobre las que se asienta la edificación principal. En dos grabados del XVI de Nicolaas de Bruyn (Primavera y Las Edades del Hombre: $X X)$ se refleja la misma idea: una edificación defensiva rodeada por agua con un jardin construido en un recinto separado del castillo y con escasa relación compositiva con el mismo. En Las Edades del Hombre ni siquiera parece existir un puente de acceso directo al jardín, mientras que en La Primavera éste se sitúa al otro lado del puente, a un lado, aglutinando espacios para plantación floral, huerto y cercado para animales (donde aparece un pozo con un mecanismo tipo shadufpértiga y contrapeso- para extraer el agua). Los grabados de Adriaan Collaert representan sin embargo espacios con una ordenación axial más precisa. En Mayo un jardín de cuadros bajos de plantación adornado con estatuaria se estructura alrededor de una fuente central. Sus limites están formados por una típica avenida arbolada que lo separa de una extensión de agua; al fondo, un túnel de verdor con nichos y en primer término, una serie de pesquerias en línea que definen un eje transversal. La fachada de la vivienda se sitúa en un eje ortogonal al de acceso, al contrario de lo que ocurre en Abril, grabado que muestra en fecha temprana una caracteristica escena holandesa, con jardines al borde de un río sobre el que se abren túneles de verdor y pabellones. ${ }^{4}$ En La Primavera de Hendrick van Schoel a los elementos anteriores se les añade uno nuevo: una isla circular para plantación, con un solo árbol situado en su centro.

\section{Los motivos acuáticos en la tratadistica de la época.}

Todo parece indicar, sin embargo, que la información visual de más envergadura que se tiene para el estudio del jardin de la época procede de la tratadística. La obra de Hans Puec ${ }^{5}$ y en mayor medida la de Hans Vredeman de Vries, ${ }^{6}$ que hará asequible al gran público la gramática clásica y erudita, proporcionará un vocabulario que permanecerá popular a lo largo de todo el siglo XVII.

En el siglo XVII en el jardin aparecerán además temas en relación con algunos tratados alemanes populares en Holanda, como los de Joseph Furttenbach. ${ }^{7}$ El arquitecto clasicista Philips Vingboons tratará también el tema del jardín en su libro de diseños, ${ }^{8}$ y el jardinero francés André Mollet, a servicio del estatúder Frederik Hendrick de Orange- Nassau alrededor del año 1633, se inspirará en los jardines

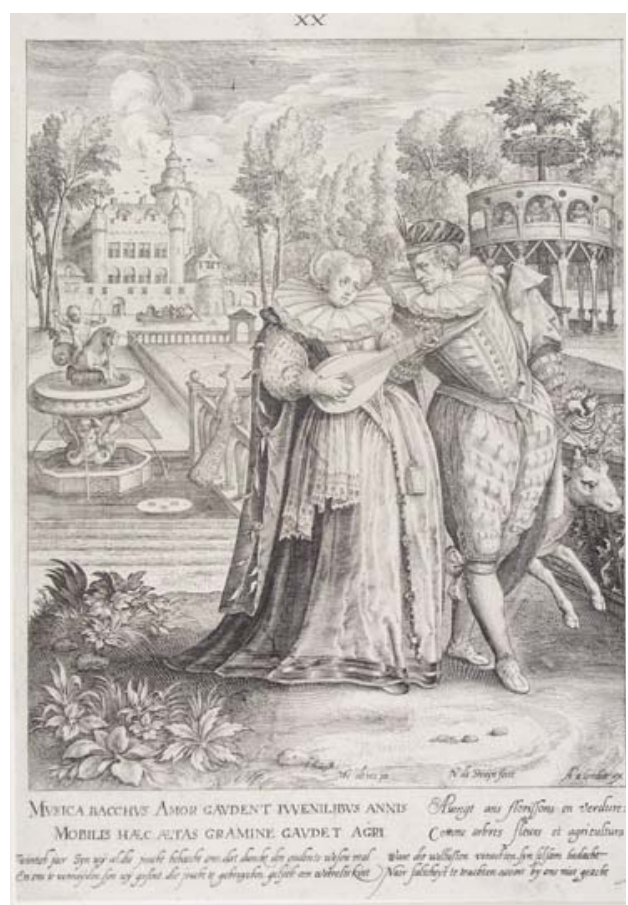



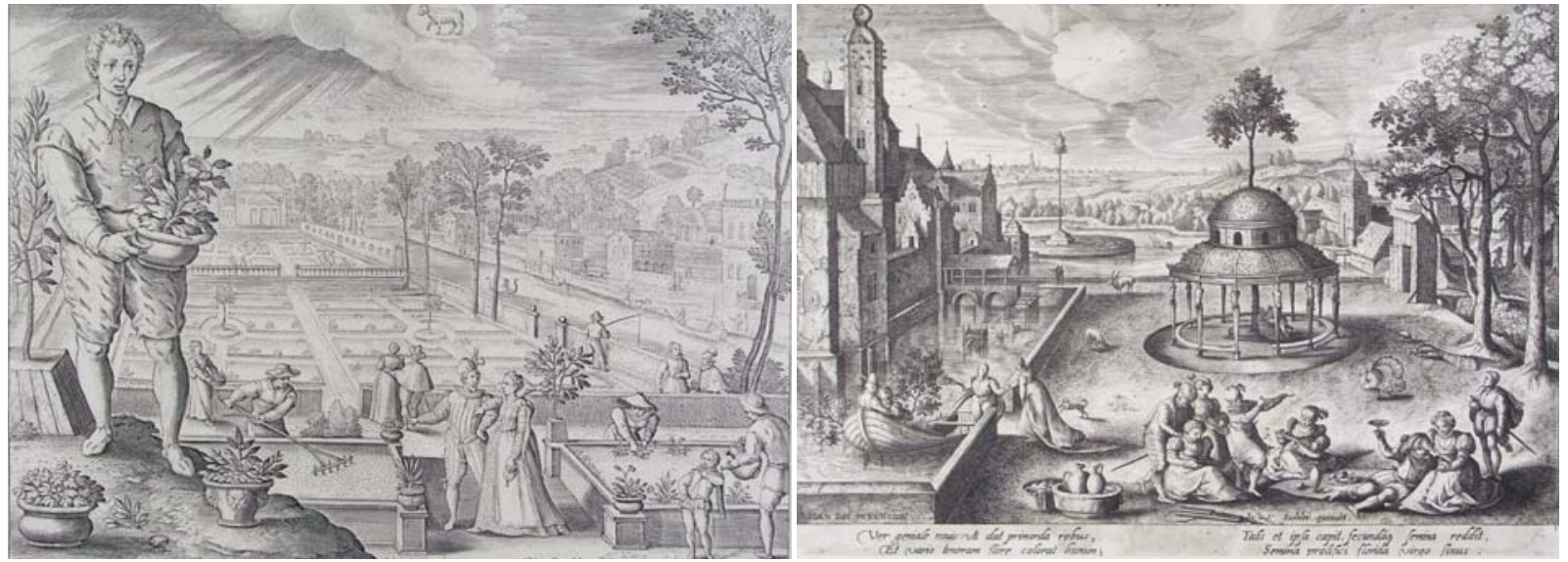

Izquierda. Adriaen Collaert. Abril .S. XVI.

Derecha. Hendrick van Schoel.

Primavera. S. XVI

Izquierda. Grabado de Hans Puec (1593))

Izquierda. Jardin con parterres en bastida de Furttenbach, Architectura recreationis (1641). holandeses para algunos de sus diseños de su famoso tratado Le jardin de Plaisir. ${ }^{9}$ Posteriormente, el tratado de Jan van der Groen (1669) propondrá soluciones para las casas de campo neerlandesas, en las que el autor tendrá en consideración las peculiares características geográficas del lugar, como el exceso de agua, los fuertes vientos o la presencia de dunas y que tendrán como resultado diseños compartimentados e introvertidos. ${ }^{10}$

En una primera categoría de imágenes, todas ellas con representaciones perspectivas, se encuentran como temas invariantes diferentes formas de edificaciones rodeadas de agua. De ellas es especialmente singular la del tratado de De Vries ya que sorprendentemente, en el mismo la presencia de agua se limita casi exclusivamente a las fuentes (un elemento que no será habitual en los jardines holandeses construidos hasta mediados del XVII). Sólo en uno de sus grabados se puede apreciar una edificación construida sobre el agua, que será sin embargo un importante tema derivado de situaciones defensivas anteriores, mantenido aún cuando la protección ya no era necesaria y que tendrá un largo recorrido posterior en la arquitectura neerlandesa de jardines. Puec ofrece una variante amable con un ligero templete en sustitución del castillo, tema no nuevo, sino interpretación de los muchos ya realizados desde la Antigüedad clásica. En cualquier caso, la existencia de plataformas elevadas y pabellones sobre el agua que proporcionaban vistas más extensas es reiteradamente comentada por los viajeros que, como Sir William Brereton (16041661), ${ }^{11}$ recorrian Holanda en el XVII. ${ }^{12}$ Aunque debian de ser elementos muy característicos de los jardines holandeses de la época, su construcción en madera hace que de ellos no queden más restos que su representación en algunos grabados. ${ }^{13}$

Los tratados de Furttenbach reproducirán jardines en recintos amurallados a modo de bastidas, que muestran una singular variante del tema del foso y tendrán interesantes repercusiones posteriores en jardines holandeses del XVII. ${ }^{14}$ Otros elementos como las grutas con artificios y juegos de agua pudieron tener una influencia directa en algunos jardines cortesanos de la Haya. 15

No obstante, frente a los anteriores temas acuáticos, con el foso en un papel destacado, será el canal actuando como elemento
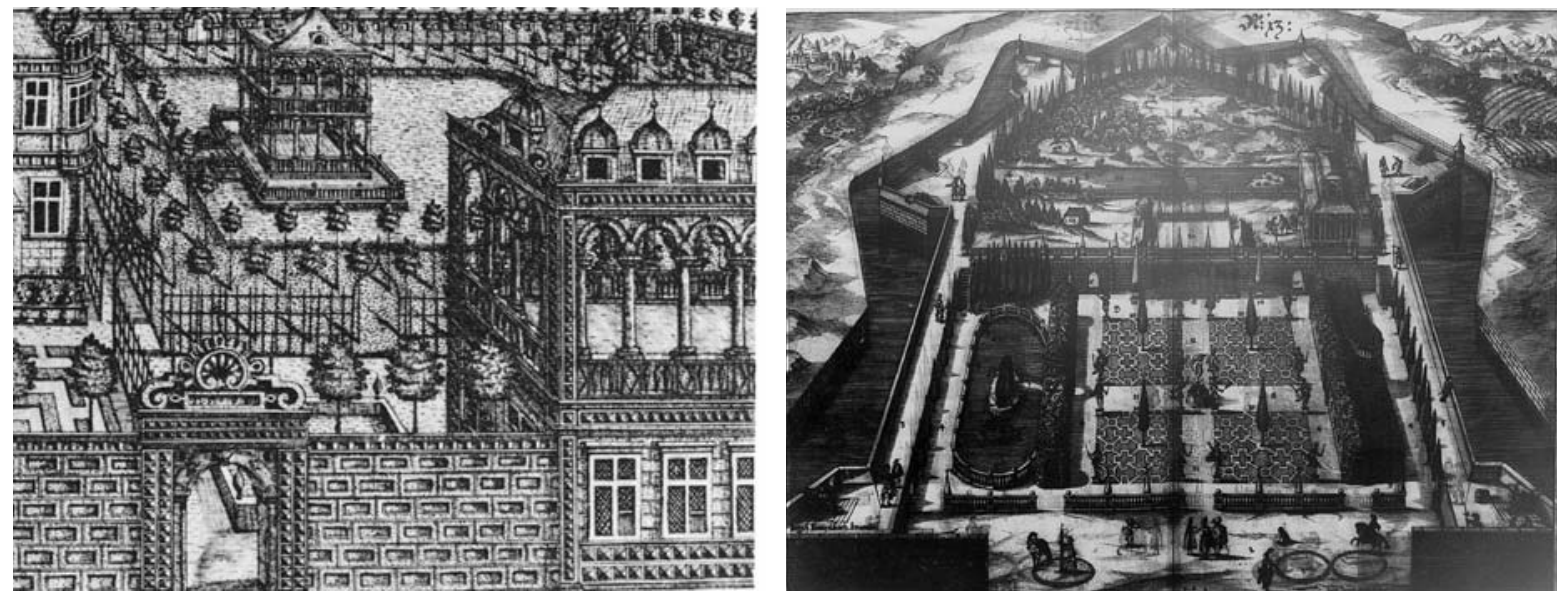
Diseños de Philips Vingboons para casas de campo ideales (1665).

Charleval según Du Cerceau (1576).

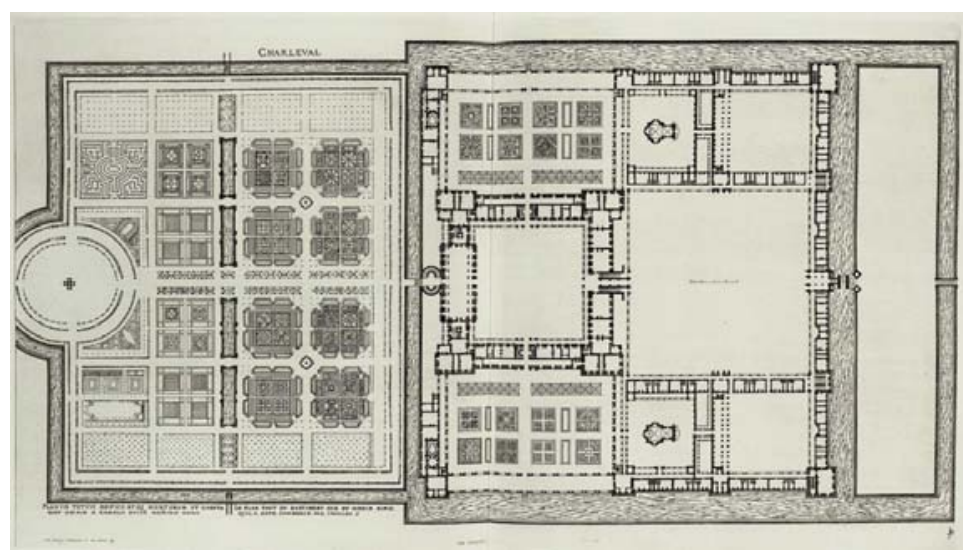

delimitador el otro tema fundamental. Su importancia se puede ver sobre todo en las primeras representaciones en planta en las que ya se aprecia su valor estructural, ligado muchas veces a la idea de foso separador. Aunque en uno de sus grabados, recién comentado, Puec da una ejemplificación de recinto octogonal con canal perimetral y templete en centro (que evoca composiciones anteriores, como la de la Villa Adriana, por ejemplo), los modelos en los que el canal se aprecia como configurador de todo un sistema aparecen claramente reflejados en el tratado de Vingboons. En los dos únicos dibujos en los que el arquitecto se aproxima al diseño del jardin, aparecen dos ideas fundamentales: por un lado, la delimitación total del recinto del jardín mediante un canal que sustituiría teóricamente al vallado y por otro la creación, asimismo con el empleo de canales, de recintos interiores como subdivisiones del jardín. El puente es el elemento obligado de conexión entre recintos. Igual que Stevin en su ciudad ideal, Vingboons parece aquí querer aplicar los nuevos principios renacentistas sobre las soluciones características de la casa de campo con jardín holandesa, cuya estructura estaba determinada por la presencia de los canales, imprescindibles para hacer el territorio habitable. Los jardines, sometidos a estos condicionantes, tenían un tamaño limitado, configurándose mediante recintos cuyo carácter aislado se enfatizaba por la disposición de altos setos o alineaciones arbóreas en su perímetro, necesarias como protección contra los fuertes vientos. Vingboons recogió estos temas para sus propuestas ideales, pero en su aparente simplicidad añadió importantes matices a los ejemplos anteriores, poco tratados hasta el momento. Las matemáticas le sirvieron para ordenar un trazado fundamentado en el empleo del cuadrado que muestra interesantes propuestas compositivas. En uno de los ejemplos se recurre a una composición centralizada en la que el canal no tiene una anchura homo-

\section{nuevo al módulo cuadrado, por un peque-} ño canal transversal, sobre el que se sitúa de forma singular la casa, que ocupa la posición de un puente de unión entre los dos ámbitos centrales (plaza y parterre). En ambos casos, la composición está contenida en un espacio perfectamente delimitado por un canal exterior acompañado de alineaciones arbóreas. En los dos ejemplos de Vingboons parecen entreverse interesantes posibilidades para ordenar el jardin de canales, aunque no necesariamente todas se desarrollaron posteriormente. Un singular precedente es Charleval. Iniciado en 1570 para el rey Carlos IX, su muerte en 1574 hizo que el proyecto nunca llega- 
Izquierda. El jardín ideal $n^{\circ} 1$ de André Mollet (1651).

Galerías y pesquerias en la obra de Hans Puec (1593).

Derecha.

Honselaarsdijck en el tratado de Van der Groen (1670). $\mathrm{r}$
$\mathrm{a}$

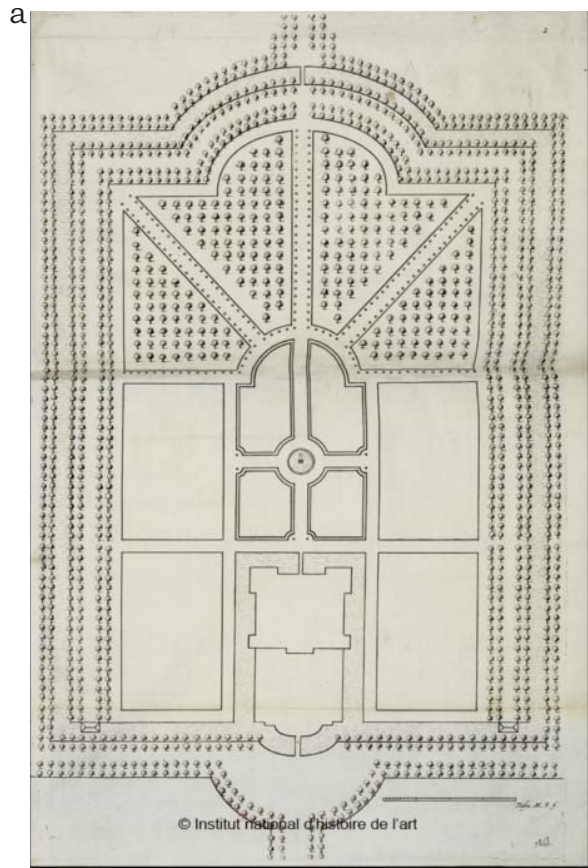

realizarse; a pesar de ello, aparece representado en la obra de Du Cerceau (1576). Aunque su escala es monumental, por primera vez el canal se emplea como elemento claramente delimitador y a la vez configurador de todo un conjunto de espacios que, en este caso, se ordenan a lo largo de un eje.

Más tardiamente Mollet (1651), en su influyente tratado, integrará las dos ideas principales en el modelo para su jardin ideal $\mathrm{n}^{\circ}$ 2: el canal delimitador y el foso que rodea la construcción, presentando además el tema de la extensión de la casa

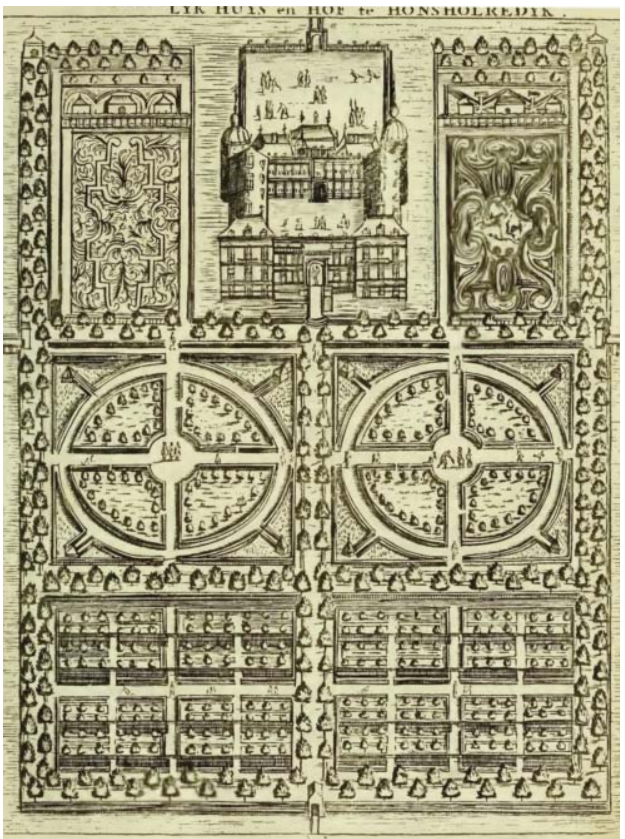

mediante una explanada de honor (o avant cour) rodeada también de agua. Un trazado con grandes similitudes a éste aparecerá en el construido jardín de Honselaarsdijk (reproducido Van der Groen en su obra de 1670). ${ }^{16}$ Aunque tradicionalmente se ha atribuido su proyecto a Mollet, posiblemente sea, anterior, y por tanto quizás constituya el primer ejemplo de este novedoso tema de explanada y edificación rodeadas de agua. ${ }^{17}$

Frente a estas ideas fundamentales, los tratados recogen también toda una serie de temas menores que, como estanques, fuentes o galerias, merecen mencionarse aunque en general no presentan novedades respecto a soluciones conocidas, como el embarcadero representado en el grabado de de Vries. Puec dibujará diversos estanques de formas cuadrangulares con función de pesquerías. Entre ellos destaca uno inusual: un estanque situado en el

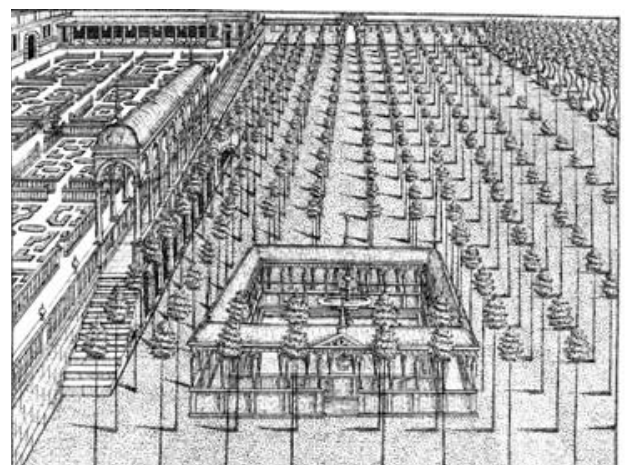

centro de un recinto arbolado, rodeado por un doble pórtico cubierto, abierto hacia el interior y el exterior en sus cuatro lados. La superficie delimitada por el pórtico está ocupada en su totalidad por el estanque (su uso probable sería el de pesqueria) que contiene en su centro una fuente de tazas, en una composición muy singular, que no tiene referentes construidos en el jardín holandés del XVII.

También en el tratado de Furttenbach y en el de Van der Groen aparecen fuentes elaboradas que tuvieron dificil adaptación al territorio holandés, con abundancia de agua pero totalmente plano. A pesar de ello, científicos como Isaac Beeckman (1588-1639) mostraron un gran interés por este tema y su técnica, aunque la fuente no se convirtió en un elemento compositivo principal del jardín holandés hasta el reinado de Guillermo III. ${ }^{18}$

Finalmente, los tratados de De Vries y Puec muestran, como otros grabados del XVI ya vistos, uno de los elementos más representativos del jardín holandés: las 
Fuentes en galeria de Furttenbach (1628).

Fuentes en el tratado de Van der Groen (1570)

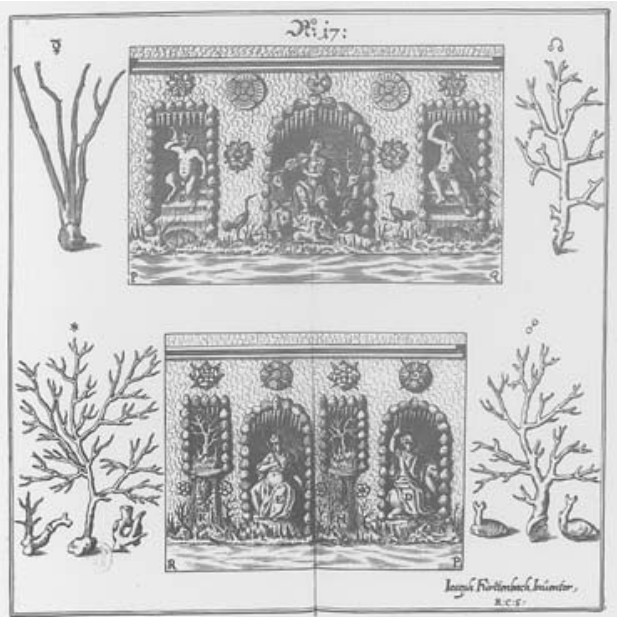

galerías o túneles de verdor que acompañaban los bordes de los elementos acuáticos, descritas asimismo por Erasmo. El Metropolitan Museum de Nueva York conserva una copia de una de las obras más influyentes del momento, el libro de modelos de Isaac Leschevin, Portals et Palisades, en el que se presentann 12 variantes para enrejados arquitectónicos y celosías. Editado en Utrecht en 1625 y dedicado a Frederik Hendrik, sus motivos tendrán una aplicación directa en alguno de sus jardines.
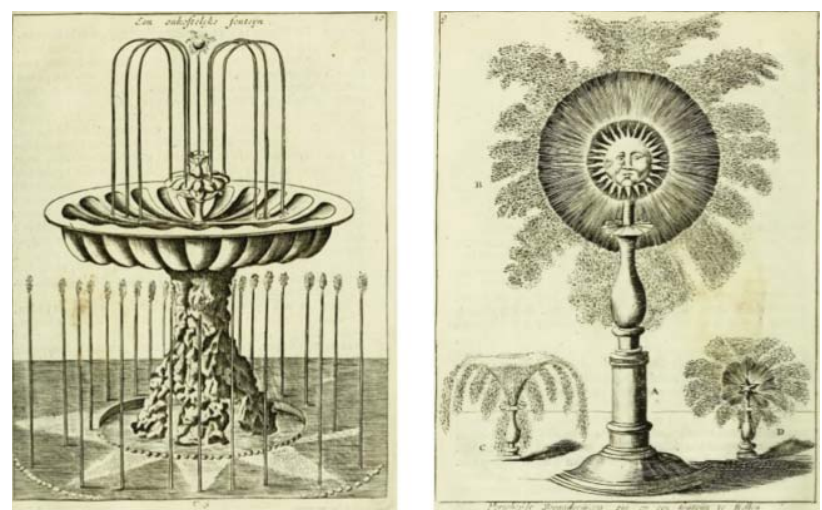

Notas

1 Jong 2000, 17. Incluso Marnix y Lipsius fueron jardineros.

2 Erasmus 1965, 50- 53

3 En Poppelsdorf, Gebhard Truchsess von Waldburg (1547- 1601), principe elector de Colonia, poseía un castillo con jardin que fue tomado durante la guerra de Colonia (15831589). Está claramente dibujado en un grabado de la batalla con su doble cerramiento de agua.

4 Estos pabellones o tuinkoepels aparecen de forma repetida en el jardín holandés, ocupando cualquier espacio disponible. En muchas ocasiones se sitúan próximos a los canales y ríos, o incluso sobre las murallas a las afueras de las ciudades, desde donde se tenía una visión privilegiada del territorio desecado (Cremers 1973, 23-24).

5 A Hans Puec se le atribuye un libro de diseños

de jardín fechado en 1593 cuya única copia se conserva actualmente en los archivos Dumbarton Oaks. Se compone de 56 imágenes y tres hojas de instrucciones sobre el trazado y mantenimiento de jardines para la realeza. Poco se sabe del autor, que quizás era originario del este de Europa o Alemania. La dedicatoria del libro puede hacer referencia al emperador Rodolfo II de Praga, para quien Vredeman de Vries y su hijo trabajaron. Se supone que Puec copió algunos de los diseños nunca publicados de de Vries, aunque sus dibujos tienen un mayor nivel de detalle y virtuosismo (Dixon, Jong 1988, 120). También aparecen elementos acuáticos más variados y complejos que en el tratado de De Vries.

$6 \quad$ El tratado de Vredeman de Vries, Hortorum viridariorumque (editado por primera vez sobre 1583) fue enormemente popular en los Países Bajos, el Báltico e incluso la Corte de Praga. Su autor, inspirado por ejemplos clásicos e italianos, fue el primero en situar el jardín renacentista del norte de Europa en un marco teórico y definirlo como una construcción arquitectónica exterior (Jong 2000, 17). Sus diseños se han interpretado como los mejores ejemplos del jardin manierista flamenco, formado por espacios autónomos ordenados axialmente y cerrados por celosías y galerias de reminiscencias medievales (Jellicoe, Goode, Lancaster 1986, 391).

7 En concreto, Architectura privata (1628) y Architectura recreationis (1641). En éste último Furttenbach realizará una imaginativa adaptación de los jardines de las villas italianas a las condiciones geográficas y climáticas del norte de Europa (Bezemer- Sellers 2001, 157).

8 Vingboons 1665

9 Mollet 1651

10 Jong 2000, 24. A pesar de este intento de adaptación al clima holandés, llama la atención el hecho de que la presencia de agua se reduzca en sus grabados casi exclusivamente a fuentes más o menos elaboradas (a excepción de los elementos acuáticos que aparecen en los dos jardines construidos que reproduce: Honselaarsdijck y Huis te Nieuburch). Por razones elementales de presión, el territorio plano holandés no propicia de forma natural el impulso necesario para su elevación en surtidores.

11 Brereton 1844.

12 Dixon, Jong 1988, 43

13 Un ejemplo particularmente interesante, por su relación con algunos jardines españoles, es uno de los grabados de Jacob Cats (1655). Poeta y político relevante de la Edad de Oro neerlandesa, tuvo un gran interés por el jardín. Fue el primer propietario de Zorgvliet, propiedad con singulares elementos acuáticos dignos de un estudio particular.

14 Muchos jardines holandeses se desarrollaron en bastidas que los protegian de las inundaciones. También los espacios libres junto a las murallas de ciudades de Holanda y Flandes se trataron como espacios ajardinados con alineaciones arbóreas que llamaban la atención de los visitantes, sobre todo ingleses, que recorrian el país en el XVII (Dixon Hunt 1990, 185-186).

15 La relación entre la obra de Furttenbach y los jardines holandeses ha sido señalada por Bezemer- Sellers $(2001,157)$.

16 Van der Groen 1669.

17 El papel de André Mollet como responsable del trazado de los parterres y no del proyecto, asi como la existencia de planos anteriores a la llegada del jardinero francés a la corte holandesa ha sido puesto de manifiesto por BezemerSellers (2001, 35-37).

18 Beeckman hizo experimentos en algunos jardines para incorporar fuentes inspiradas en textos clásicos o en realizaciones contemporáneas, como las de Salomon de Caus (Jong 2000, 31). También Huygens, asesor artístico de Frederik Hendrik, viajó por el centro y sur de Europa, 
visitando jardines con elementos acuáticos que influirán en sus proyectos y en los del estatúder. En Heidelberg tuvo la ocasión de conocer y admirar los juegos de agua del Hortus Palatinus antes de su destrucción en 1620 (BezemerSellers 2001, 157).

\section{Bibliografia}

Grabados de los siglos XVI y XVII. Colección Museo Boijmans van Beuningen.

Bezemer-Sellers, Vanessa. 2001. Courtly Gardens in Holland 1600-1650: the house of Orange and the Hortus Batavus. Amsterdam: Architectura \& Natura Press; Woodbridge: Garden Art Press.

Brereton, Sir William. 1844. Travels in Holland, The United Provinces, England, Scotland, and Ireland, by Sir William Brereton. Londres: Chetham Society.

Cats, Jacob. 1655. J. Cats Ovderdom, buyten-leven, en Hof-gedachten, op Sorgh-vliet. Amsterdam: J.J. Schipper.

Cremers, C.M. Otoño 1973. Our Heritage: the Dutch Garden, an introduction to its history. Garden History vol. 2, $\mathrm{n}^{\circ} 1$ : 10- 29

Dixon Hunt, John. 1990. The Dutch Garden in the Seventeenth Century. Washington D.C.: Dumbarton Oaks Research Library and Collection.

Dixon Hunt, John; Jong, Eric de. 1988. The anglodutch garden in the age of William and Mary. De Gouden eeuw van de Hollandse tuinkunst. Londres: Taylor \& Francis.

Erasmus, Desiderius.1965. The Godly Feast. En The Colloquies of Erasmus. Transl. Craig R.

Furttenbach, Joseph. 1628. Architectura civilis. Ulm: J. Saurn.

Furttenbach, Joseph. 1641. Architectura privata. Augspurg: J. Schultes

Groen. Jan van der. 1670. Den Nederlandtsen Hovenier. Marcus Doornick, Amsterdam.

http://caliban.mpiz-koeln.mpg.de/groen

Jellicoe, Geoffrey \& Susan; Goode, Patrick; Lancaster, Michael. 1986. The Oxford Companion to Gardens. Oxford: Oxford University Press.

Jong, Erik A. de. 2000. Nature and Art: Dutch Garden and Landscape Architecture, 1650- 1740. Philadelphia: University of Pennsylvania Press.

Mollet, André. c. 1665. Le Jardin de Plaisir.

Vingboons, Philips. 1665. Gronden en afbeeldsels der voornaamste gebouwen. Amsterdam: Clement de Jonge.

Vredeman de Vries, Hans. 1615. Hortorum viridariorumque elegantes et multiplices formae ad architectonicae artis normam affabre deliniatae. J. Bussemacher excudebat, Coloniae, 1615.

h t t p : / / a r c hit e c t u r a . ces r . u n i v tours.fr/Traite/Images/LES0948Index.asp 